\title{
O Ensino de Ciências na Perspectiva da Metodologia de Aprendizagem por Projetos em Curso de Licenciatura
}

Luiz Everson da Silva luiever@gmail.com $0000-0002-2332-3553$ Universidade Federal do Paraná Matinhos, Paraná, Brasil.

Lenir Maristela Silva lenirbotanica@gmail.com $0000-0003-0076-0651$ Universidade Federal do Paraná, Matinhos, Paraná, Brasil.

\begin{abstract}
RESUMO
Este artigo tem o propósito de apresentar argumentos a favor da metodologia de ensino por projetos para a formação emancipatória dos sujeitos de aprendizagem. Para a construção das argumentações relatam-se as atividades desenvolvidas durante um semestre numa turma de Licenciatura em Ciências da UFPR Litoral. Além disso, utilizam-se as narrativas dos estudantes na avaliação final do semestre, buscando identificar as marcas diferenciais no processo percebido pelos mesmos. Destacaram-se os principais argumentos a favor da metodologia: há um favorecimento da pró-atividade dos estudantes, pois as aulas do tipo palestra deixam de ser o foco metodológico; o professor atua como mediador na medida em que junto com os estudantes organiza o estudo e as responsabilidades coletivas e individuais; a aprendizagem se dá num processo dialético em que se parte e se chega na prática social, possibilitando que o objeto deixe a assepsia conteudista e permita a construção de elaborações de pensamentos críticos a cerca de realidade concreta. À construção deste trabalho permitiu também a conclusão de que não é o uso da metodologia por projetos em si que favorece a formação emancipatória, mas a mediação, cuja lógica filosófica possibilite a elaboração de pensamentos críticos.
\end{abstract}

PALAVRAS-CHAVE: Aprendizagem por Projetos. Ensino de Ciências. Formação Emancipatória. 


\section{INTRODUÇÃO}

O pensar crítico sobre os processos naturais e humanos é de fundamental importância para o desenvolvimento de ações modificadoras da realidade local/regional. Com isso, (re) significar o espaço acadêmico de modo que ele possa, efetivamente, estar voltado para a formação de sujeitos reflexivos, participativos e cidadãos é uma premissa de uma educação que realmente almeje a melhoria das condições de vida. Por outro lado, os conteúdos e metodologias historicamente construídos no ensino de Ciências têm passado por críticas e revisões permitindo a elaboração e a consecução de novas concepções de projetos educativos. A antiga necessidade de priorizar as meras descrições dos fenômenos naturais e transmissão de definições, regras, nomenclaturas e fórmulas - muitas vezes, sem estabelecer vínculos com a realidade do estudante ou outros contextos, tem dado espaço à construção de processos pedagógicos no qual o conteúdo científico está permeado dos aspectos cognitivos, emocionais e sociais deste processo. Embora isso não seja novidade (FREIRE, 2001) o que prevalece na educação superior no Brasil ainda é um ensino de ciências de reprodução de conhecimento (ANDRÉ , 2002; GOLDBACH e ELHANI, 2008).

Essa problemática não tem se dado apenas no ensino de Ciências, mas no ensino de modo geral. A caminho de mudanças, diante das inúmeras críticas e relatórios, também está o MEC, pois recentemente (novembro de 2013) a Câmara dos Deputados Federais aprovou o relatório sobre o projeto de Lei (PL 6840/2013) que determina que a grade curricular seja dividida por áreas de conhecimento e não mais por disciplinas. $O$ texto prevê a universalização da educação em tempo integral em um prazo de dez anos, reorganiza o currículo por áreas (linguagens, matemática, ciências da natureza, humanas e formação profissional) e amplia para quatro anos a duração do ensino médio noturno (BRASIL, 2013).

Nesse sentido, conteúdos e metodologias devem se integrar efetivamente entre as competências necessárias à formação, ou seja, devem levar o estudante a produzir, levantar dúvidas, pesquisar, enfim, criar relações que incentivam novas buscas, descobertas, compreensões e reconstruções de conhecimento.

A possibilidade de selecionar temas relevantes com os alunos, assuntos ligados ao meio ambiente, à visão do universo, à saúde e à transformação científico-tecnológica do mundo, bem como à compreensão do que são a ciência e a tecnologia, permite aos estudantes conhecer as bases lógicas e culturais que apoiam as explicações científicas, bem como discutir as implicações éticas e os alcances dessas explicações na formulação de visões de mundo.

Nesta perspectiva, uma possibilidade metodológica interessante de trabalhar os conhecimentos de forma integrada é a aprendizagem por projetos. Partindo de problematizações é possível vincular os temas à realidade circundante. Ao enfocar tal proposta pretende-se unir no mínimo três pressupostos de aprendizagem: visão sistêmica, abordagem progressista e ensino com pesquisa (BEHRENS e JOSÉ, 2001). A partir do tema selecionado, os estudantes são motivados a refletir sobre as suas próprias concepções. Estas diferem entre si e são carregadas pela sua cultura, religião, história de vida, profissão, família. É essa sinergia que enriquece a discussão e o processo como um todo e precisa ser valorizada. Da mesma forma a superação de concepções simplistas acerca do tema está intimamente relacionada 
(re)construção do conhecimento na perspectiva da complexidade e da dinamicidade do real concreto.

A observação de fenômenos da natureza, a relação com os sujeitos, com o local e o regional faz com que o estudante exercite a tolerância com culturas e comportamentos diferentes dos seus e o coloca numa situação de aprendizagem ligada à condição do ambiente em que vive.A partir dessas considerações acreditase que seja extremamente importante a troca de experiências a cerca de metodologias que possibilitem a melhoria do ensino de Ciências. Este ensaio, portanto, tem o objetivo de apresentar argumentos a favor da metodologia de ensino por projetos para a formação emancipatória dos sujeitos de aprendizagem. Para a construção das argumentações relatam-se as atividades desenvolvidas durante um semestre numa turma de Licenciatura em Ciências da UFPR Litoral. Além disso, utilizam-se as narrativas dos estudantes na avaliação final do semestre, buscando identificar as marcas diferenciais no processo percebido pelos mesmos. O Curso de Licenciatura em Ciências da UFPR Litoral atua com um Projeto Político Pedagógico fundamentado na metodologia por projetos e numa concepção de educação emancipatória (SILVA, SILVA e BRIZOLLA, 2013).

\section{Saúde e Qualidade de Vida do Adolescente Caiçara:exercitando a aprendizagem por projetos}

A temática do projeto que será descrito tem como foco a saúde e a adolescência. De acordo com os Parâmetros Curriculares Nacionais (PCN), o tema Saúde é considerado transversal no currículo escolar, ou seja, com possibilidade de ser abordado em todas as disciplinas. Porém, os conteúdos de Educação em Saúde são prioritariamente trabalhados dentro das disciplinas Ciências ou Biologia, com enfoque na transmissão de informações sobre doenças, seus ciclos, sintomas e profilaxias (BRASIL, 1998). Alguns debates tem se estendido sobre o tema Saúde na escola. Podemos destacar a reflexão de Focesi (1990) ao afirmar que a responsabilidade dos docentes é enorme, cabendo a estes colaborar para o desenvolvimento do pensamento crítico do estudante, além de contribuir para que os jovens adotem comportamentos saudáveis.

Diniz e colaboradores (2010) mencionam que as questões de saúde, a falta de abordagens multidisciplinares da temática na escola, bem como a falta de qualificação dos professores são grandes obstáculos para a promoção da saúde.

Nesta mesa linha, Leonello e L'Abbate (2006), afirmam que o professor tem que estar bem preparado, bem formado pelos cursos de graduação das universidades. A sensibilização e a formação do corpo docente têm importância fundamental para que a Educação e Saúde existam de fato e sejam bem trabalhadas dentro das escolas. O que acontece em muitas situações, é que professores não têm sido preparados para abordar a temática saúde na escola e algumas vezes não sabem como tratar os temas, ou evitam debater determinados assuntos considerados polêmicos, e, além disso, em geral, não têm apoio da escola nem dos pais.

Um dos obstáculos para a consolidação de uma nova forma de abordagem deste tema é discutida por Precioso (2004), que realiza pesquisa a respeito dessa temática em Portugal. Segundo o autor as dificuldades residem no fato de não haver um currículo transversal de saúde, na forte tradição de organização 
curricular vertical, e também, na falta de formação inicial e continuada e sensibilização dos professores.

Já a adolescência é compreendida pela maior parte dos estudiosos do desenvolvimento humano como um período de mudanças físicas, cognitivas e sociais que, juntas, ajudam a traçar o perfil desta população (FROTA, 2007). É na adolescência que, sob diversos ângulos, vemos conceitos e atitudes serem substituídos: são novas maneiras de se pensar, de se relacionar, de se comunicar e de se movimentar. Esses indícios sinalizam para o amadurecimento do ser humano e para a sua inserção na vida adulta (PIAGET, 1998).

A partir dessas reflexões, na sequência, passamos a descrever o trabalho por projetos Saúde e Qualidade de Vida do Adolescente Caiçara com estudantes do segundo ano do Curso de Licenciatura em Ciências da UFPR Litoral durante o segundo semestre de 2011.

Nas duas primeiras semanas de aula (12 horas/aulas semanais) construiu-se a temática e o contrato didático. Iniciamos o projeto através da elaboração de um mapa conceitual sobre as vivências e leituras dos estudantes no período de férias e as vivências que tiveram no estágio supervisionado do semestre anterior. A partir desse mapa construiu-se o projeto da Turma intitulado "Saúde e qualidade de vida do adolescente caiçara". Na sequência, foi construído um contrato didático, onde os professores responsáveis pela mediação na turma apresentaram uma minuta como proposta. A partir da discussão da minuta e dos interesses coletivos se firmou o contrato. Behrens e José (2001) relatam que a discussão do projeto tornase significativa, nesta fase inicial, pois o docente apresenta aos estudantes uma minuta de proposta, que elaborou e submetem à apreciação dos alunos, já denominada por Perrenoud (1999) como contrato didático. O docente precisa ter clareza que há necessidade de apreciar e reconstruir, se necessário e pertinente, a proposta com os alunos. A aceitação das opiniões dos alunos numa relação dialógica é importante e relevante para o sucesso da produção do conhecimento. Os alunos que ainda não estão habituados a participar de um processo participativo encontram algumas dificuldades de se manifestar com receio de sofrerem repressões ou constrangimento na sala de aula. O docente precisa esclarecer o processo crítico, participativo e dialógico que irá caracterizar o projeto desde a fase inicial.

Inicialmente os estudantes optaram por assistir o documentário "A dieta do palhaço" em que o diretor Morgan Spurlock decide ser a cobaia de uma experiência: se alimentar apenas em restaurantes da rede fast food, realizando neles três refeições ao dia durante um mês. Durante a realização da experiência o diretor fala sobre a cultura do fast food nos Estados Unidos, além de mostrar em si mesmo os efeitos físicos e mentais que os alimentos deste tipo de restaurante provocam.

Após um intenso debate e estudos sobre os fundamentos teóricos suscitados pelo filme foi combinado que haveria uma aula de elaboração e degustação de pizzas no LEAL/UFPR (Laboratório de Alimentos). Após essa aula os estudantes passaram a construir os "caminhos dos alimentos" e seus nutrientes, ou seja, aspectos alimentares fisiológicos e bioquímicos. Para isso, foram montados grupos em que elaboraram desenhos da trajetória dos alimentos no tubo digestivo. 
Como contraponto à alimentação fast food os estudantes propuseram realizar um jantar a moda caiçara. A UFPR Litoral se localiza em Matinhos, cidade do litoral paranaense, cujas origens remontam à população caiçara. Segundo Diegues (1998) população caiçara refere-se a todos os indivíduos e comunidades do litoral dos Estados do Paraná, São Paulo e Rio de Janeiro.

Para isso, foi realizada uma pesquisa dos alimentos caiçaras e montado um cardápio, onde os estudantes prepararam os pratos para degustarem no Laboratório de Alimentos. Nas aulas seguintes os estudantes se propuseram a pesquisar durante o estágio quais eram os cardápios da merenda escolar nas escolas da rede estadual. Ao trazerem os resultados dessa pesquisa iniciaram estudos para entender o contexto da merenda escolar (políticas, cardápios, determinantes históricos sociais...). Em seguida, passaram a analisar os livros didáticos no se referia aos temas trabalhados e com um olhar sobre alimentação saudável e sustentável. Para isso, teve que estudar tanto a temática alimentação saudável e funcional, quanto da alimentação não saudável e contaminada. A partir disso, passou-se à revisão do contrato didático e proposições dos próximos temas de estudo.

Como uma das questões que eles estavam trazendo da vivência de estágio eram a indisciplina e violência na escola, eles escolheram como temas para próximos estudos o desenvolvimento do adolescente, os conflitos e os transtornos afetivos que podem acontecer nessa fase. Elegeram então o filme "Aos treze". Esse filme relata a fase adolescente de Tracy (Evan Rachel Wood) que é uma adolescente inteligente e uma aluna brilhante. Um dia ela se torna amiga de Evie (Nikki Reed), a garota mais popular da escola. Esta amiga a apresenta ao submundo do sexo, das drogas e da mutilação, o que cria uma nova Tracy e a coloca em conflito com seus colegas, professores e, principalmente, com sua mãe (Holly Hunter). Após várias discussões e estudos de temáticas despertadas pelo filme como: anatomia e fisiologia do cérebro do adolescente; autonomia dos pais na escola; relação entre prazer e adolescência; motivação e autonomia do adolescente, os estudantes decidiram organizar uma mesa redonda sobre a adolescência e o uso das drogas. Para isso, empreenderam vários estudos e organizaram o evento. Convidaram um psicólogo, um servidor de escola e uma enfermeira. $\mathrm{O}$ evento aconteceu quase no final do semestre e pela avaliação dos estudantes foi um sucesso. Ao final, realizou-se uma avaliação do semestre no qual os estudantes tiveram a oportunidade de relatar suas impressões desta caminhada para sua formação.

\section{A Perspectiva dos Estudantes no Projeto Vivido}

$\mathrm{Na}$ perspectiva de percorrer um caminho de reflexão-ação dialeticamente com estudantes de licenciatura em ciências construiu-se o projeto anteriormente citado com o intuito de criar significado, analisar circunstâncias e desenvolver o espírito de investigação a partir do conhecimento do que já foi produzido sobre o tema proposto. Para Dewey (1968), na metodologia por projetos os estudantes terão que pesquisar, discutir, elaborar e especialmente, discernir entre o que é ou não relevante para construir conhecimento durante o processo. 0 professor deixa de ser aquele que ensina para ser um mediador na (re)construção do conhecimento, para que o aluno possa encontrar sentido naquilo que está aprendendo. Entende-se como mediação na perspectiva dialética o sentido de 
negação do imediato na relação com o mediato, ou seja, busca-se a superação do imediato, sem que a primeira seja anulada pela segunda; ao contrário, o imediato está presente no mediato. A negatividade da mediação é responsável pela reflexão recíproca de um termo no outro. O papel do professor nesse caso é o de problematizador, já que na metodologia por projetos a pesquisa é o princípio educativo. Os momentos coletivos com os estudantes não podem prescindir do diálogo. A consolidação da proposta pode ser observada na avaliação do semestre pelo estudante $A$ :

O tema Saúde e Qualidade de Vida do adolescente caiçara, já me deixou curiosa, pois vivemos aqui há vários anos, sendo assim eu fui um legítimo adolescente caiçara, mas eu não tinha conhecimento de como a vida de um adolescente é confusa. Pensava que sua ideias eram muito levianas, e que a simples contradição pudesse causar tantos danos e as influencias que tomam lugar em seus pensamentos. Pude conhecer melhor o adolescente, neste semestre com as resenhas e reflexões, pude perceber detalhes que muitas vezes não observamos, como suas carências. 0 estágio me proporcionou uma melhor visão e entendimento do aluno e como lidar com o aprendizado e suas transformações.(ESTUDANTE A)

Fica claro também na avaliação do estudante a importância de estabelecer uma conexão com suas vivencias de estágio, visto que o mesmo é realizado concomitante às aulas.

Oliveira (1997) ressalta que os docentes geralmente não conhecem as características do desenvolvimento dos estudantes, o que pode dificultar o trabalho de questões ligadas à saúde. Com relação ao processo de formação docente, Oliveira e Lopes Silva (1990), destacam que o processo de formação dos docentes é falho nessa área, geralmente centrado nas práticas pedagógicas transmissoras de informações desvinculadas da realidade. Daí aplicar uma metodologia baseada em projetos em conjunto com a vivência do estágio permite o diálogo com os fundamentos teórico-práticos, que empiricamente já os constituem. Esse diálogo se expande ao abarcar outras dimensões do processo educativo (SILVA, SILVA e BRIZOLA, 2013).

A escolha do tema destaca o aspecto do território do litoral paranaense e sua população caiçara. Nesse sentido, considera-se no processo educativo não apenas os conteúdos oriundos da Ciência, mas também os da Etnociência. Esses últimos são saberes abandonados, substituídos e desqualificados pela tradição científica, que mesmo relegados a um campo inferior continuam sendo utilizados por populações chamadas tradicionais. Esses saberes populares também chamados de senso-comum ou saberes da tradição e representam a manifestação de um conhecimento que não está nos livros. Mas nem por isso, devem ser menosprezados, afinal a "Ciência" vem de onde? A discussão sobre a importância e a validade desses conhecimentos tem sido feita por vários autores dentro de uma tendência que visa fazer desaparecer a distinção hierárquica entre o conhecimento cientifico (racional) e o conhecimento do senso comum. É nesse contexto que surgem como tendência os estudos em etnociências (BASTOS, 2013).

Sabe-se que além do estilo de vida, alguns itens ligados às condições de vida, tais como o acesso aos sistemas de saúde e à escolaridade, a exposição aos riscos ocupacionais e ambientais e as oportunidades de trabalho também influenciam o modus vivendi de uma sociedade (MINAYO et al., 2000; LESSA, 1999). O tema saúde é tido como transversal a ser trabalhado e assumido com responsabilidade 
no projeto de toda a escola; alunos, professores e o ambiente escolar tornam-se sistematicamente elementos chaves para essa realização. A escola saudável deve ser entendida como um espaço vital gerador de autonomia, participação, crítica e criatividade, para que o estudante tenha a possibilidade de desenvolver suas potencialidades físicas, psíquicas, cognitivas e sociais (PELICIONI, 1999).

Considerar tais aspectos enriquece a discussão, pois permite orquestrar uma aliança entre a aprendizagem individual e coletiva. Assim o estudante pode transitar, integrando diferentes aspectos da realidade local. Alcântara e Behrens (2001), contribuem para essa discussão ao elencarem as categorias abaixo: Abordagem Progressista: Relação dialógica, crítica, reflexiva, com ações articuladas, trabalho coletivo e busca da transformação da realidade; Abordagem do Ensino com Pesquisa: Parceria dos alunos e professor na busca da produção do conhecimento e na superação da cópia e da reprodução e; Abordagem Holística ou Sistêmica: Reaproximação das partes na busca da visão do todo, de um sistema integrado e interconectado.

O relato do estudante $B$ destaca a necessidade de aprofundamento de alguns dos temas. Fica claro que o professor necessita criar possibilidades para investigar recursos variados que levem o aluno a aprender a aprender, como e onde buscar a informação e com isso como elaborar e produzir o seu próprio conhecimento.

\begin{abstract}
Com esse projeto tive um maior aprofundamento...soube o que era adolescência normal, descrito no texto (os desafios da adolescência) para discutirmos o que era esse adolescente normal. Acredito que deveríamos nos aprofundar no desenvolvimento fisiológico e neuropsicológico dos adolescentes, relacionando essa temática com os transtornos afetivos e de aprendizagem e a influência do meio social (instituições sociais) para esse desenvolvimento.(ESTUDANTE B)
\end{abstract}

O destaque de uma das atividades aparece no relato do estudante C. Esta atividade se encaixa na contextualização que permite ao grupo localizar historicamente a temática.

O que mais me marcou foi a mesa redonda em que os participantes colocaram sobre o adolescente na vida real, e dando vários exemplos e vivências de como o adolescente pode se expressar na sociedade de um modo geral e também dependendo do convívio em que ele está inserido sendo familiar, cultural.(ESTUDANTE C)

A possibilidade de ampliação de visão de homem/mulher e de mundo é destacada no relato do estudante $D$ que fortalece a visão deste enquanto sujeito de sua aprendizagem. São as ações do sujeito que o coloca em uma situação de aprendizagem. E essas ações estão ligadas a interação dele com o ambiente natural e social.

\footnotetext{
...são conhecimentos riquíssimos que poderemos contextualizar dentro da escola no dia-a-dia, nos fez refletir sobre as metodologias que podem ser aplicadas na sala de aula para motivar os alunos com qualidade. Confesso que até para minha vida uma das temáticas está servindo "Motivação/Autonomia na Adolescência". Não sabia que a baixa serotonina prejudica a motivação do adolescente. (Estudante D)
}

O relato do estudante $E$ reforça o desenvolvimento de habilidades relacionais, de convivência, de reflexão sobre seus valores, formas de comportamento, de enxergar o outro. 
Tudo que pesquisei neste semestre foi muito bom, pois meu conceito de que os adolescente de hoje são mais mal educados do que os de minha época é errado, pois são iguais....a questão é que os adultos é que devem tentar compreender esta etapa da vida, que tem grande influência são os professores e amigos no seu comportamento. Para facilitar a compreensão do sentido do certo e do errado pode ter uma intervenção ou orientação, como os aspectos sociais, físicos, ambientais e alimentares, tudo isto se faz compreender que o adolescente precisa de muita atenção para ajudá-los a serem adultos responsáveis.(ESTUDANTE E)

A sala de aula é um espaço social no qual se pretende fazer uma caminha dialógica de construção de saberes a partir de interações e significados trazidos pelos sujeitos (alunos e professores) que estão em um determinada esfera social, geográfica.

A caminhada pautada na pesquisa enquanto princípio educativo pode ser evidenciada no relato do estudante E e F. Ao adotarmos a metodologia de aprendizagem baseada em projetos, temos como premissa básica o conhecimento da história de vida dos estudantes e da problematização da realidade local, preferencialmente, utilizando-se das diferentes áreas do conhecimento das Ciências da Natureza e da Educação, com potencial possibilidade de construção de novos saberes. O Projeto não é uma atividade proposta pelo professor com tema dirigido resultando numa mera apresentação de trabalho, mas algo construído coletivamente pela turma, mediado pelos professores;

\footnotetext{
...equilíbrio de matérias durante o semestre, estou falando do equilíbrio entre o ato de ser e vivenciar a docência e o conteúdo ciência em si.No começo do semestre estava muito ligado ao conteúdo ciências, ou seja, esta interessado em química, biologia, geologia (pelo trabalho do 2o.período. Mas hoje aprendi a vivenciar o ato de ser professor, sobre o que planejar para uma aula prática em uma sala de aula, como lidar com situações adversas com o adolescente de $5 \mathrm{a}$. a 8a. série em diferentes escolas, soube como funcionava a mente de um adolescente caiçara.(ESTUDANTE F)
}

Aprendi muito, pude fazer relações dos temas com assuntos do cotidiano, nos projetos que eu trabalho e pude colocá-los em prática. Mesmo não gostando de fazer resenhas eu aprendi muito estudando os alimentos funcionais e o processo digestório. Outro tema que eu me interessei foi a psicologia do adolescente. Como funciona esse processo tão delicado cheio de alterações e mudanças. (Estudante G)

\section{Reflexão Final}

É necessário que o Ensino das Ciências em geral, seja capaz de educar os seres humanos numa fraternidade que se estenda a todos os demais, independente de preconceitos que se constituem como tal, a partir da diversidade cultural e econômica e do interesse de poucos. Cultura e conhecimento científico geram poder, e está nas mãos dos educadores a possibilidade de construir uma sociedade-mundo. A consciência não é inata, pode ser construída a partir do conhecimento científico e suas relações com a aplicação social. Uma vez apreendida pode modificar de maneira significativa o modo como vemos e sentimos. Pode também produzir cidadãos protagonistas, que ao tomarem posse do conhecimento científico e de sua utilidade, serão capazes de escolher e assumir, além de uma futura profissão, seu papel social. Negar este conhecimento aos menos favorecidos, com a alegação de que eles não se interessam por ele, é 
condená-los a permanecer na situação em que se encontram, é negar-lhes o acesso ao poder. É neste ponto, que os professores da área científica (Química, Física, Biologia), tem grande responsabilidade. Não é possível ensinar Ciência hoje, como no século passado (ZULIANI, 2007). É esta Ciência, dinâmica, constituída de dilemas complexos e polêmica que se torna interessante aos olhos de nossos alunos e que por este motivo deve ser trabalhada. Além disso, é indispensável levar em consideração os saberes das populações tradicionais e não-tradicionais, para formar indivíduos com identidades próprias e capazes de conviver num mundo repleto de diversidade. 


\title{
The Science Education in the Perspective of Learning Methodology for Project Degree Curse
}

\begin{abstract}
This article aims to present arguments in favor of teaching methodology for emancipatory projects for the training of subject learning. For the construction of arguments reported in the activities developed during a semester in a class of Science Degree at the UFPR Coastline Sector. Furthermore, it uses the narratives of students in the final evaluation of the semester in order to identify the differential marks in the process perceived by them. The highlights were the main arguments in favor of the methodology : there is a favoring of proactivity students because the lessons of the lecture type no longer the methodological focus; the teacher acts as a mediator to the extent that along with the students organizing the study and the collective and individual responsibilities; learning occurs in a dialectical process in which one party and arrives in social practice, allowing the object to leave the content- aseptic and allow the construction of elaborations critical thoughts about reality . The construction of this test also allowed the conclusion that it is not the use of the methodology by which projects itself promotes emancipatory education, but the mediation whose philosophical logic enables the development of critical thinking.
\end{abstract}

KEYWORDS: Education Projects. Science Education. Emancipatory Formation 


\section{REFERÊNCIAS}

ALCÂNTARA, P. e BEHRENS, M. Pacto: Aprendizagem colaborativa com tecnologia interativa. Anais... CDROM, Curitiba: PUCPR,, 2001.

ANDRÉ, M. E. D. A. (ORG.). Formação de professores no Brasil (1990-1998). Brasilia: MEC/Inep/Comped, , 2002.

BASTOS, S. N. D. Etnociências na sala de aula: uma possibilidade para aprendizagem significativa. Anais... XI Congresso Nacional de Educação EDUCERE, o IV Seminário Internacional sobre Profissionalização Docente - SIPDCátedra UNESCO e o II Seminário Internacional de Representações Sociais, Subjetividade e Educação - SIRSSE. Curitiba: PUCPR, 2013.

BEHRENS, M. A. e JOSÉ. M. M. Aprendizagem por Projetos e os Contratos Didáticos. Revista Diálogo Educacional. V.2, N.3, pág.77-96, 2001.

BRASIL. Câmara dos Deputados. Projeto de Lei PL 6840/2013. Altera a Lei no 9.394, de 20 de dezembro de 1996, que estabelece as diretrizes e bases da educação nacional, para instituir a jornada em tempo integral no ensino médio, dispor sobre a organização dos currículos do ensino médio em áreas do conhecimento e dá outras providências. Disponível em: $<$ http://www.camara.gov.br/proposicoesWeb/prop_mostrarintegra?codteor=12 00428\&filename=PL+6840/2013>. Acesso em: 02/08/2014.

BRASIL. Ministério da Educação e Cultura. Secretaria de Educação Fundamental. (1998). Parâmetros curriculares nacionais: terceiro e quarto ciclos: apresentação dos temas transversais, Brasília (1998).

DEWEY, J. O sentido do projecto. IN: LEITE, MALPIQUE, SANTOS. Trabalho de projecto. Leitura comentada, Porto/Potugal: Edições Afrontamento, 1993).

DIEGUES, A. C. S. Diversidade biológica e culturas tradicionais litorâneas: o caso das comunidades caiçaras. Série Documentos e Relatórios de Pesquisa, n. 5 São Paulo: NUPAUB-USP, 1998.

Diniz, M.C.P., Oliveira, T.C. \& Schall, V.T. Saúde como compreensão de vida: avaliação para inovação na educação em saúde para o ensino fundamental. Rev. Ensaio, v.12, Pág. 119-144, 2010. 
Focesi, E. Educação em Saúde na escola. O papel do professor. Revista Brasileira Saúde do Escolar, V.1, N.2, Pág. 4-8, 1990.

FREIRE, Paulo. Pedagogia dos sonhos possíveis. São Paulo: Editora Unesp, 2001.

FROTA, A.M.M.C. Diferentes concepções da infância e adolescência: a importância da historicidade para sua construção. Estudos e pesquisas em Psicologia, V.7, N.1, PÁG. 147-60, 2007.

GOLDBACH, T.; EL-HANI, C. N. Entre receitas, programas e códigos: metáforas e ideias sobre genes na divulgação científica e no contexto escolar. Alexandria Revista de Educação em Ciência e Tecnologia. V.1, N.1, Pág. 153-189, 2008.

Leonello, V.M. \& L'Abbate, S. Educação em Saúde na escola: uma abordagem do currículo e da percepção de alunos de graduação em Pedagogia. Interface. V.10, N.19, Pág. 149-166, 2006.

LESSA, I. Doenças crônico não-transmissíveis: bases epidemiológicas. In: ROUQUAYROL, M.Z.; ALMEIDA FILHO, N. Epidemiologia \& Saúde. 5ạed. Rio de Janeiro: Medsi, 1999.

MINAYO, M.C.S.; HARTZ, Z.M.A.; BUSS, P.M. Qualidade de vida e saúde: um debate necessário. Ciência \& Saúde Coletiva, V.5, N.1, Pág.7-18, 2000.

OLIVEIRA, M. L. C. Concepções, dificuldades e desafios nas ações educativas em saúde para escolares no Brasil. Revista Divulgação Saúde Debate, v.18, pág.4350, 1997.

OLIVEIRA, M. L. C.; LOPES SILVA, M. T. A. Educação em Saúde: repensando a formação de professores. Revista Brasileira de Saúde Escolar, V.1, N.2, Pág. 3-20, 1990.

PELICIONI, M.C.F. As inter-relações entre educação, saúde e meio ambiente. Jornal da USP, São Paulo, V.5, série, 494, N.2, 1999.

PERRENOUD, P. Construir as Competências Desde a Escola. Porto Alegre: Artes Médicas Sul, 1999.

PIAGET, J. Seis estudos de psicologia, Rio de Janeiro:Forense Universitária, 1998. 
Precioso, J. Educação para a saúde na universidade: um estudo realizado em alunos da Universidade do Minho. Revista Electrónica Enseñanza de las Ciencias, V.3, N.2, Pág. 161-170, 2004.

SILVA, L. M. Metodologia para o ensino de Botânica: o uso de textos alternativos para a identificação de problemas da prática social. RBEP-Rev. Bras. Est. Pedag., V.88, N.219, Pág. 242-256, 2007.

SILVA, L.M. ; SILVA, L.E.; BRIZOLLA, F. Projeto Pedagógico do Curso de Licenciatura em Ciências da Ufpr Litoral: Desafios e Possibilidades Para Uma Formação Emancipatória. Rev. Bras. Est. Pedag. V. 94, N. 234, Pág. 524-541, 2013.

ZULIANI, S. R. Q. A. Cultura, Ciência, Conhecimento Químico e Formação de Valores: Implicações para o conhecimento escolar (2007). Disponível em <http://www.faac.unesp.br/extensao/forum/textos forum/silviazuliani.html> Acesso em 20/08/2014.

Recebido: 12 abri. 2015

Aprovado: 26 jul. 2016

DOI: http://dx.doi.org/10.3895/rbect.v9n2.1915

Como citar: SILVA, L. E. ; SILVA, L. M. O Ensino de Ciências na perspectiva da Metodologia de

Aprendizagem por Projetos em Curso de Licenciatura. Revista Brasileira de Ensino de Ciência e

Tecnologia, v. 9, n. 2, 2016. Disponível em: <https://periodicos.utfpr.edu.br/rbect/article/view/1915>. Acesso em: $x x x$

\section{Correspondência:}

Direito autoral: Este artigo está licenciado sob os termos da Licença Creative Commons-Atribuição 4.0 Internacional. 